\title{
The Relationship between Health Facility-based Delivery and Child Mortality in Nigeria: Insights from 2013 Nigeria Demographic and Health Survey
}

\author{
Bolaji Samson Aregbeshola ${ }^{1, *}$, Samina Mohsin Khan² \\ ${ }^{1}$ Department of Community Health \& Primary Care, College of Medicine, University of Lagos, Idi-Araba, Mushin, Lagos, Nigeria \\ ${ }^{2}$ Department of Public Health Sciences, Karolinska Institutet, Stockholm, Sweden \\ *Corresponding author: bolajiaregbeshola74@gmail.com
}

\begin{abstract}
Background: Health facility-based delivery has been considered to be an important factor in reducing maternal and child deaths. Evidence suggests that 63 per cent of women aged 15-49 years deliver at home. This study seeks to examine the effect of health facility-based delivery on child mortality in Nigeria. Methods: Secondary data from the 2013 Nigeria Demographic and Health Survey was used. Variables on place of delivery as well as demographic and socio-economic characteristics of the study sample were analysed. Data analysis was carried out using STATA 12. Univariate, bivariate and multivariate analyses were conducted. Results: Results showed that health facility-based delivery was not significantly associated with child mortality. However, being a child of women aged 25-34 years, being a child of women aged 35 years or older, being a child of a woman with secondary or higher education, being a child of a woman living in rural area, being a child of a woman living in North West region, being a child of a woman living in South East region, being a child of a married woman, being a child of a woman with more than five members, being a child of a woman with 2-4 birth order, being a child of a woman with five or more birth order, being a child of a woman with 3 and 4 children and being a child of a woman with five or more children were significantly associated with child mortality. Conclusions: Our study concludes that health facility-based delivery is not a significant predictor of child mortality in Nigeria. However, demographic and socio-economic factors were significantly associated with child mortality. Therefore, policy makers need to target these factors in their effort to reduce child mortality.
\end{abstract}

Keywords: health facility-based delivery, child mortality, population-based survey, Nigeria

Cite This Article: Bolaji Samson Aregbeshola, and Samina Mohsin Khan, "The Relationship between Health Facility-based Delivery and Child Mortality in Nigeria: Insights from 2013 Nigeria Demographic and Health Survey.” American Journal of Public Health Research, vol. 6, no. 1 (2018): 4-10. doi: 10.12691/ajphr-6-1-2.

\section{Introduction}

Child mortality is a public health problem in both developed and developing countries. Globally, it is estimated that 5.8 million children under 5 years of age died at the end of 2015. [1] Also, 2.6 million neonatal deaths were reported in 2015 around the world. [1] Africa has the highest risk of child mortality before completing five years with an average of 81 per 1000 live births. [2] However, sub-Saharan Africa (SSA) has the highest level of child mortality in the world with 1 in 9 children dying before age five, more than 16 times the average for developed regions. [3] In 2015, mortality rate for children aged 1-4 years was about 2.5 million in SSA. [1] Global efforts to reduce child mortality led to the establishment of Millennium Development Goal (MDG) 4 target which aimed to reduce under 5 mortality by two-third between 1990-2015 as well as the Sustainable Development Goal (SDG) 3.2 with targets of reducing under 5 mortality to fewer than 25 deaths per 1000 live births, decreasing neonatal mortality to fewer than 12 deaths per 1000 live births and ending preventable deaths of new-borns and children younger than 5 years, all by 2030. [1] Although, the MDG 4 target led to substantial reduction in child mortality around the world but most low and middle income countries (LMICs) in SSA fell short of achieving MDG 4 target recording rates exceeding 100 per 1000 live births. [1] Evidence suggests that Nigeria had the second largest number of under 5 deaths $(726,600)$ in the world after India in 2015. [1] In 2017, World Health Organization (WHO) estimates that infant mortality is 69 deaths per 1000 live births, under 5 mortality is 109 deaths per 1000 live births while neonatal mortality is 34 deaths per 1000 live births. [4] Though Nigeria has also made some gains over the decades in reducing child mortality but the progress has been slow. In addition, there is variation in under 5 mortality rates across Nigeria ranging from 72 deaths per 1000 live births in Edo State to 209 deaths per 100 live births in Zamfara State at the end of 2013. [5] Numerous studies on the determinants of child mortality have been conducted in LMICs including Nigeria. [6-20] Findings of these studies showed 
that a number of factors are associated with child mortality. In spite of the numerous studies on the determinants of child mortality in Nigeria and elsewhere, child mortality remains a major public health challenge besides it continues to be a subject of debate around the world.

Health facility-based delivery has been considered to be an important factor in reducing maternal and child deaths. WHO recommends skilled assistance with delivery and this can be achieved when pregnant women deliver in a health facility. Health facilities are expected to have skilled health workers that can manage complications that may arise at the time of delivery or refer the mother to the next level of care. According to Nigeria Demographic and Health Survey (NDHS) in 2013, 63 per cent of pregnant women aged 15-49 years delivered their babies at home without any antenatal care (ANC) visit. [21] The situation is critical in North East and North West regions of Nigeria where over $79 \%$ of pregnant women aged 15-49 delivered their babies at home. [21] Over $60 \%$ of pregnant women in Bayelsa, Plateau and Niger States delivered at home rather than a health facility. [21] While previous studies have shown that some factors are associated with health facility-based delivery, [22-30] there is limited evidence on the impact of health facility-based delivery on child mortality in Nigeria.[31] Studies conducted on the impact of health facility-based delivery on child mortality elsewhere have shown that health facility-based delivery reduce the risk of child mortality. [32,33,34,35,36] Hence, the need for a study focusing on health facility-based delivery as the main predictor variable of child mortality in Nigeria to generate new knowledge on how best to address the problem of child survival. This study aims to examine the relationship between health facility-based delivery and child mortality in Nigeria. The study contributes to knowledge and the scarce literature focusing on this topic as well as inform policy decision towards reduction in child mortality as well as improved health infrastructure and health service delivery.

\section{Methods}

\subsection{Data Source}

Secondary data from the 2013 NDHS was used for the study. NDHS is a nationally representative cross-sectional study conducted by the National Population Commission (NPC) with funding by United States Agency for International Development (USAID), the United Kingdom Department for International Development (DFID) through Partnership for Transforming Health Systems Phase II (PATHS2), and the United Nations Population Fund (UNFPA) with technical support from ICF International. The NDHS 2013 provides updated estimates of some of the basic demographic and health indicators covered in the earlier surveys such as fertility levels, marriage, fertility preferences, awareness and use of family planning methods, child feeding practices, nutritional status of women and children, adult and childhood mortality, awareness and attitudes regarding HIV/AIDS, in addition, to information on violence against women.

\subsection{Study Design}

This was a retrospective cross-sectional study of 18,712 live births during the five years preceding the survey.

\subsection{Data Collection}

Relevant data for the study were extracted from the 2013 NDHS dataset using simple random sampling and stratification techniques. Among the numerous variables in the dataset, only fifteen variables were selected for the purpose of this study. The data were thereafter cleaned, recategorized and recoded as necessary.

\subsection{Variables Measurement}

\subsubsection{Dependent Variable}

The dependent and/or outcome variable in this study is child mortality measured by under-five mortality (coded as 1 if dead and 0 if alive) which is defined in this study as the probability of dying between age 0 and five years.

\subsubsection{Independent Variables}

The independent and/or explanatory variables were guided by Andersen's Behavioural Model, [37] MosleyChen Model [38] and literature review on the impact of place of delivery on child mortality.[31-36,39] In the Andersen's Behavioural Model, the variables that determine the demand for health care are categorized into: predisposing factors (age, sex, ethnicity and household head characteristics); enabling factors (location, geopolitical zone, education, health insurance status and household income); and need factors (perceived severity of illness, self-reported health status, presence of physician diagnosing chronic diseases and overweight). In the Mosley-Chen Model which is an analytical framework for the study of the determinants of child survival in the developing countries including Nigeria, the variables that determine child mortality are categorized into: individuallevel variables (i.e. individual productivity - at mothers or fathers' level as well as traditions/norms/attitudes); household-level variables (e.g. income and wealth) and community-level variables (i.e. ecological setting; political economy and health system). These variables operate at various levels through the proximate determinants (i.e. the intermediate factors) to influence childhood mortality. The Mosley-Chen Model provides the link between child mortality determinants (i.e. independent variables at individual, familial and community levels), the proximate factors (i.e. intermediate variables) and the child survival.

In our study, the main independent variable is the place of delivery which was defined according to the survey questionnaire and recoded as at home and health facility. The following are the cofounding variables: maternal age refers to the age of women at the time of the household survey and was categorized as 15-24, 25-34 and $35+$. Maternal education refers to the highest level of education attained by the mother and was categorized into no education, primary education and secondary or higher education. Place of residence refers to the location of a woman's residence and was grouped into urban and rural areas. Nigeria is also grouped into six geo-political zones: 
North Central, North East, North West, South East, South West and South South. Socio-economic status (SES) was constructed using household wealth index based on asset variables such as house ownership, land ownership, ownership of a car, type of dwelling place, number of rooms occupied, material of wall of dwelling, floor of dwelling, roof of dwelling, type of fuel for cooking, source of lighting, location of kitchen, source of drinking water and type of toilet facility used. These variables were summed up for each household and their members. The final scores were used for grouping into wealth quintile as poorest, poorer, middle, richer and richest. Marital status describes the type of marital relationship the mother was in and was categorised as never married, married, living with partner, widowed, divorced and separated. Religion refers to the religious affiliation of mothers and was recoded as Christian, Islam and Others. Maternal occupation describes the type of employment women were engaged in and was recoded as not working, professional/cleric, sales/agriculture/self-employed and manual worker. Family size was defined according to the survey questionnaire and recoded as less than five members and more than five members. Birth order was defined according to the survey questionnaire and recoded as first birth, 2 to 4 birth order and five or higher birth order. Parity was defined according to the survey questionnaire and recorded as less than 3 children, between 3 to 4 children and five or more children. Gender of household head was defined according to the survey questionnaire and recorded as male and female.

\subsection{Statistical Analysis}

Data were analysed using STATA 12. Descriptive statistics was used to analyse the demographic and socioeconomic characteristics of the study sample as well as the outcome variable in the form of frequency tables and simple percentages. Chi square analysis was used to test for associations between independent variables and child mortality. Thereafter, multivariate logistic regression was used to examine associations between the dependent variable (child mortality) and the independent variables (place of delivery, maternal age, maternal education, place of residence, geo-political zone, socio-economic status, marital status, religion, maternal occupation, family size, birth order, parity and gender of household head). Using the equation in the binary logistic regression model:

$$
\mathrm{y}=\beta_{o}+\beta_{i} X_{i}+\beta_{2} X_{2}+\beta_{3} X_{3} \ldots . \beta_{n} X_{n}+E_{i}
$$

Where $\mathrm{y}$ is the outcome/dependent variable, $\beta_{o}$ is the constant/intercept, $\beta_{i} \ldots \beta_{n}$ are the regression coefficients and the $X_{i} \ldots X_{n}$ are a collection of independent/explanatory variables and $E_{i}$ is the error term. Tests were done at a confidence level of $95 \%$ and at $5 \%$ significance level.

\subsection{Ethical Consideration}

In obtaining the micro data, a request was made on the DHS program website on September 10, 2017 and approval was granted to download the data on the same day, hence, there were no ethical issues of concern. Issues of informed consent, confidentiality, anonymity and privacy of the study sample were addressed by the Institutional Review Board (IRB) of ICF Macro International in the United States and Nigeria Health Research Ethics Committee (NHREC) of the Federal Ministry of Health (FMOH).

\section{Results}

\subsection{Descriptive Statistics}

Table 1 presents the outcome variable and the socio-demographic characteristics of respondents. Out of the 18712 live births during the five years preceding the survey, 1,140 children had died. With respect to place of delivery, only (37.66\%) of children were delivered in a health facility while (62.34\%) were delivered at home. The majority of study sample (46.39\%) were children of mothers aged 25-34 years. With respect to maternal education, (44.98\%) of children belong to mothers who had no education, (20.64\%) were children of mothers with primary education and (34.38\%) were children of mothers with secondary or higher education. Majority of the study sample (66.11\%) were children of mothers living in rural area while only (33.89\%) are children of mothers living in urban area. Respondents consisted of households and individuals from the six geo-political zones: North Central (15.63\%), North East (19.44\%), North West (30.42\%), South East (8.57\%), South South (12.61\%) and South West (13.33\%). As high as (90.77\%) of the study sample are children of women who are married. More than half of children (56.6\%) were from Muslim family while only (41.90\%) of children were from Christian family. A total of $(72.7 \%)$ of children were from households with family size of five or more people while only (27.3\%) of children had a family size of less than five members. Almost half of the children (43.95\%) were of 2-4 birth order while only (38.42\%) of the children were of five or higher birth order. Most of children (39.38\%) were from households with parity less than three children while (31.65\%) of children were from households with parity of between 3 and 4 children. Only (28.97\%) of children were from households with parity of five or more children. As high as $(88.17 \%)$ of children were from male headed households while $(11.83 \%)$ of children were from female headed households.

\subsection{The Relationship between Health Facility-based Delivery and Child Mortality}

Table 2 shows the bivariate analysis of the relationship between health facility-based delivery and child mortality. There was a statistically significant association between child mortality and variables such as place of delivery, maternal age, maternal education, place of residence, geo-political zone, socio-economic status, marital status, religion, maternal occupation, family size, birth order and parity. However, gender of household head was not significantly associated with child mortality. Only variables that were statistically significant with the outcome variable were included in the multivariate analysis. 
Table 1. Outcome variable and socio-demographic characteristics of respondents

\begin{tabular}{|c|c|}
\hline $\begin{array}{l}\text { Demographic and Socio- } \\
\text { economic Characteristics }\end{array}$ & $\begin{array}{l}\text { Respondents }(\%) \\
\quad(N=18,712)\end{array}$ \\
\hline \multicolumn{2}{|l|}{ Outcome variable } \\
\hline \multicolumn{2}{|l|}{ Child mortality } \\
\hline Alive & 17,572 (93.91\%) \\
\hline Dead & $1,140(6.09 \%)$ \\
\hline \multicolumn{2}{|l|}{ Independent variables } \\
\hline \multicolumn{2}{|l|}{ Place of delivery } \\
\hline At home & 11,665 (62.34\%) \\
\hline Health facility & 7,047 (37.66\%) \\
\hline \multicolumn{2}{|l|}{ Maternal age } \\
\hline $15-24$ & $4,551(24.32 \%)$ \\
\hline $25-34$ & 8,680 (46.39\%) \\
\hline $35+$ & $5,481(29.29 \%)$ \\
\hline \multicolumn{2}{|l|}{ Maternal education } \\
\hline No Education & 8,417 (44.98\%) \\
\hline Primary & $3,862(20.64 \%)$ \\
\hline Secondary and higher & 6,433 (34.38\%) \\
\hline \multicolumn{2}{|l|}{ Place of residence } \\
\hline Urban & 6,341 (33.89\%) \\
\hline Rural & $12,371(66.11 \%)$ \\
\hline \multicolumn{2}{|l|}{ Geo-political zone } \\
\hline North Central & $2.924(15.63 \%)$ \\
\hline North East & 3,638 (19.44\%) \\
\hline North West & $5,692(30.42 \%)$ \\
\hline South East & $1,604(8.57 \%)$ \\
\hline South South & 2,359 (12.61\%) \\
\hline South West & 2,495 (13.33\%) \\
\hline \multicolumn{2}{|l|}{ Socio-economic status } \\
\hline Poorest & 4012 (21.44\%) \\
\hline Poorer & $4206(22.48 \%)$ \\
\hline Middle & 3,785 (20.23\%) \\
\hline Richer & 3,556 (19.00\%) \\
\hline Richest & 3,153 (16.85\%) \\
\hline \multicolumn{2}{|l|}{ Marital status } \\
\hline Never Married & $507(2.71 \%)$ \\
\hline Married & 16,985 (90.77\%) \\
\hline Living with partner & $548(2.93 \%)$ \\
\hline Widowed & $276(1.47 \%)$ \\
\hline Divorced & $216(1.15 \%)$ \\
\hline Separated & $180(0.96 \%)$ \\
\hline \multicolumn{2}{|l|}{ Religion } \\
\hline Christian & $7,841(41.90 \%)$ \\
\hline Islam & $10,591(56.60 \%)$ \\
\hline Others & $280(1.50 \%)$ \\
\hline \multicolumn{2}{|l|}{ Maternal occupation } \\
\hline Not working & $5,260(28.11 \%)$ \\
\hline Professional/clerical & $836(4.47 \%)$ \\
\hline Sales/Agriculture/self employed & $10,416(55.66 \%)$ \\
\hline Manual worker & $2,200(11.76 \%)$ \\
\hline \multicolumn{2}{|l|}{ Family size } \\
\hline Less than five members & $5,109(27.30 \%)$ \\
\hline More than five members & $13,603(72.70 \%)$ \\
\hline \multicolumn{2}{|l|}{ Birth order } \\
\hline First birth & $3299(17.63 \%)$ \\
\hline 2-4 birth order & 8223 (43.95\%) \\
\hline $5+$ birth order & $7190(38.42 \%)$ \\
\hline \multicolumn{2}{|l|}{ Parity } \\
\hline Less than 3 children & 7,368 (39.38\%) \\
\hline Between 3 and 4 children & $5,923(31.65 \%)$ \\
\hline 5 or more children & $5,421(28.97 \%)$ \\
\hline \multicolumn{2}{|l|}{ Gender of household head } \\
\hline Male & $16,498(88.17 \%)$ \\
\hline Female & 2,214 (11.83\%) \\
\hline
\end{tabular}

Table 2. Bivariate analysis of the relationship between health facility-based delivery and child mortality

\begin{tabular}{|l|c|c|}
\hline \multirow{2}{*}{$\begin{array}{l}\text { Demographic and Socio-economic } \\
\text { Characteristics }\end{array}$} & \multicolumn{2}{|c|}{ Child mortality } \\
\hline & Chi square & $\boldsymbol{p}$ value \\
\hline Place of delivery & 32.46 & $0.000^{*}$ \\
\hline Maternal age & 39.27 & $0.000^{*}$ \\
\hline Maternal education & 48.80 & $0.000^{*}$ \\
\hline Place of residence & 45.30 & $0.000^{*}$ \\
\hline Geo-political zone & 52.50 & $0.000^{*}$ \\
\hline Socio-economic status & 70.42 & $0.000^{*}$ \\
\hline Marital status & 12.16 & $0.033^{*}$ \\
\hline Religion & 6.97 & $0.031^{*}$ \\
\hline Maternal occupation & 8.00 & $0.046^{*}$ \\
\hline Family size & 84.18 & $0.000^{*}$ \\
\hline Birth order & 35.87 & $0.000^{*}$ \\
\hline Parity & 98.16 & $0.000^{*}$ \\
\hline Gender of household head & 0.15 & 0.697 \\
\hline
\end{tabular}

${ }^{*} \mathrm{p}<0.05$.

Table 3 present results of the multivariate analysis of the relationship between health facility-based delivery and child mortality. Children who were delivered in a health facility had reduced risk (AOR: 0.90; 95\% C.I: 0.74-1.03; $\mathrm{p}=0.119$ ) of childhood death compared with children who were delivered at home. However, there was no statistically significant association between health facilitybased delivery and child mortality. Children of mothers aged 25-34 years (AOR: 1.21; 95\% C.I: 1.00-1.45; $\mathrm{p}=0.046$ ) and 35 years and above (AOR: 2.47; 95\% C.I: 1.98-3.14; $\mathrm{p}=0.000$ ) had increased risk of childhood death respectively compared with children of mothers aged 1524 years and this was statistically significant. The risk of child mortality was reduced in children of mothers with secondary or higher education (AOR: 0.70; 95\% C.I: 0.570.86; $\mathrm{p}=0.001$ ) and this was statistically significant. Children born in rural area had increased risk (AOR: 1.36; 95\% C.I: 1.16-1.60; $\mathrm{p}=0.000)$ of childhood death compared with children born in urban area and this was statistically significant. Children born in North West region (AOR: 1.34; 95\% C.I: 1.07-1.67; $\mathrm{p}=0.009$ ) and South East region (AOR: 1.82; 95\% C.I: 1.39-2.40; $\mathrm{p}=0.000$ ) respectively were significantly associated with increased risk of childhood death compared with children born in North Central, North East, South South and South West regions. The risk of child mortality was significantly reduced for children whose mothers were married (AOR: 0.67; 95\% C.I: 0.45-0.97; p=0.037). Children who belong to households with family size of five or more people (AOR: 0.58; 95\% C.I: 0.49-0.67; p=0.000) had reduced risk of child mortality compared with children who belong to households with family size less than five members and this was statistically significant. The risk of child mortality was significantly higher for children of 2-4 birth order (AOR: 1.23; 95\% C.I: 1.02-1.50; $\mathrm{p}=0.033$ ) and five or more birth order (AOR: 6.00; 95\% C.I: 4.52-8.00; $\mathrm{p}=0.000$ ) respectively. Children from households with parity between 3-4 children (AOR: 0.24; 95\% C.I: 0.20$0.97 ; \mathrm{p}=0.000$ ) and 5 or more children (AOR: 0.08; 95\% C.I: $0.06-0.10 ; \mathrm{p}=0.000)$ respectively had lower risk of child mortality compare with children from households with parity less than 3 children and this was statistically significant. 
Table 3. Multivariate analysis of the relationship between health facility-based delivery and child mortality

\begin{tabular}{|c|c|c|c|c|c|c|}
\hline \multirow{2}{*}{$\begin{array}{l}\text { Demographic and Socio-economic } \\
\text { Characteristics }\end{array}$} & \multicolumn{6}{|c|}{ Child mortality } \\
\hline & Unadjusted OR & 95\% C.I. & $p$ value & Adjusted OR & 95\% C.I. & $p$ value \\
\hline \multicolumn{7}{|l|}{ Place of delivery } \\
\hline At home & 1 & 1 & 1 & 1 & 1 & 1 \\
\hline Health facility & 0.90 & $(0.76-1.06)$ & 0.205 & 0.88 & $(0.74-1.03)$ & 0.119 \\
\hline \multicolumn{7}{|l|}{ Maternal age } \\
\hline $15-24$ & 1 & 1 & 1 & 1 & 1 & 1 \\
\hline $25-34$ & 0.83 & $(0.69-0.99)$ & $0.044^{*}$ & 1.21 & $(1.00-1.45)$ & $0.046^{*}$ \\
\hline $35+$ & 0.40 & $(0.32-0.50)$ & $0.000^{*}$ & 2.47 & $(1.98-3.14)$ & $0.000^{*}$ \\
\hline \multicolumn{7}{|l|}{ Maternal education } \\
\hline No Education & 1 & 1 & 1 & 1 & 1 & 1 \\
\hline Primary & 0.94 & $(0.77-1.14)$ & 0.517 & 1.07 & $(0.90-1.29)$ & 0.424 \\
\hline Secondary or higher education & 1.38 & $(1.09-1.74)$ & $0.008^{*}$ & 0.70 & $(0.57-0.86)$ & $0.001^{*}$ \\
\hline \multicolumn{7}{|l|}{ Place of residence } \\
\hline Urban & 1 & 1 & 1 & 1 & 1 & 1 \\
\hline Rural & 0.78 & $(0.66-0.94)$ & $0.007 *$ & 1.36 & $(1.16-1.60)$ & $0.000 *$ \\
\hline \multicolumn{7}{|l|}{ Geo-political zone } \\
\hline North Central & 1 & 1 & 1 & 1 & 1 & 1 \\
\hline North East & 0.81 & $(0.64-1.04)$ & 0.097 & 1.23 & $(0.98-1.55)$ & 0.075 \\
\hline North West & 0.75 & $(0.59-0.95)$ & $0.017^{*}$ & 1.34 & $(1.07-1.67)$ & $0.009 *$ \\
\hline South East & 0.58 & $(0.43-0.77)$ & $0.000^{*}$ & 1.82 & $(1.39-2.40)$ & $0.000^{*}$ \\
\hline South South & 0.88 & $(0.67-1.16)$ & 0.365 & 1.15 & $(0.88-1.50)$ & 0.304 \\
\hline South West & 1.10 & $(0.83-1.46)$ & 0.494 & 0.92 & $(0.69-1.21)$ & 0.543 \\
\hline \multicolumn{7}{|l|}{ Socio-economic Status } \\
\hline Poorest & 1 & 1 & 1 & - & - & - \\
\hline Poorer & 0.99 & $(0.84-1.18)$ & 0.973 & - & - & - \\
\hline Middle & 1.19 & $(0.96-1.47)$ & 0.110 & - & - & - \\
\hline Richer & 1.02 & $(0.79-1.31)$ & 0.881 & - & - & - \\
\hline Richest & 1.33 & $(0.96-1.83 \mathrm{~s})$ & 0.084 & - & - & - \\
\hline \multicolumn{7}{|l|}{ Marital Status } \\
\hline Never Married & 1 & 1 & 1 & 1 & 1 & 1 \\
\hline Married & 1.47 & $(1.00-2.16)$ & $0.050^{*}$ & 0.67 & $(0.45-0.97)$ & $0.037^{*}$ \\
\hline Living with partner & 1.57 & $(0.93-2.67)$ & 0.094 & 0.63 & $(0.37-1.07)$ & 0.089 \\
\hline Widowed & 1.16 & $(0.65-2.07)$ & 0.615 & 0.87 & $(0.49-1.55)$ & 0.634 \\
\hline Divorced & 1.04 & $(0.56-1.93)$ & 0.909 & 0.93 & $(0.50-1.74)$ & 0.827 \\
\hline Separated & 0.99 & $(0.53-1.86)$ & 0.980 & 1.02 & $(0.54-1.90)$ & 0.955 \\
\hline \multicolumn{7}{|l|}{ Religion } \\
\hline Christian & 1 & 1 & 1 & - & - & - \\
\hline Islam & 1.07 & $(0.87-1.32)$ & 0.540 & - & - & - \\
\hline Others & 1.22 & $(0.71-2.11)$ & 0.477 & - & - & - \\
\hline \multicolumn{7}{|l|}{ Maternal occupation } \\
\hline Not working & 1 & 1 & 1 & - & - & - \\
\hline Professional/clerical & 1.03 & $(0.69-1.53)$ & 0.899 & - & - & - \\
\hline Sales/Agriculture/self-employed & 0.88 & $(0.76-1.03)$ & 0.107 & - & - & - \\
\hline Manual worker & 0.85 & $(0.69-1.05)$ & 0.140 & - & - & - \\
\hline \multicolumn{7}{|l|}{ Family size } \\
\hline Less than five members & 1 & 1 & 1 & 1 & 1 & 1 \\
\hline More than five members & 1.74 & $(1.49-2.04)$ & $0.000^{*}$ & 0.58 & $(0.49-0.67)$ & $0.000^{*}$ \\
\hline \multicolumn{7}{|l|}{ Birth order } \\
\hline First birth & 1 & 1 & 1 & 1 & 1 & 1 \\
\hline 2-4 birth order & 0.82 & $(0.68-1.00)$ & $0.046^{*}$ & 1.23 & $(1.02-1.50)$ & $0.033^{*}$ \\
\hline $5+$ birth order & 0.17 & $(0.13-0.23$ & $0.000^{*}$ & 6.00 & $(4.52-8.00)$ & $0.000 *$ \\
\hline \multicolumn{7}{|l|}{ Parity } \\
\hline Less than 3 children & 1 & 1 & 1 & 1 & 1 & 1 \\
\hline Between 3 and 4 children & 4.15 & $(3.35-5.13)$ & $0.000^{*}$ & 0.24 & $(0.20-0.30)$ & $0.000^{*}$ \\
\hline 5 or more children & 12.72 & $(9.75-16.59)$ & $0.000^{*}$ & 0.08 & $(0.06-0.10)$ & $0.000^{*}$ \\
\hline
\end{tabular}




\section{Discussion}

Our study examined the relationship between health facility-based delivery and child mortality in Nigeria. We found that health facility delivery was not a significant predictor of child mortality. A possible explanation for this finding is that mothers who deliver their child at home could have access to some form of skilled care at the time of delivery. However, this result is in line with similar studies conducted in Nigeria [31] and Malawi and Zambia [39] but in contrast with studies conducted n LMICs, [32] Bangladesh, [33] Indonesia, [34] Tanzania [35] and SSA. [36] Children of mothers aged 25-49 years were found to be significantly associated with increased risk of child mortality. This could be due to the non-utilization of maternal and child health services. However, the finding is in contrast to similar studies conducted in Ethiopia, [11] Bangladesh, [13] Nigeria [14] and Tanzania. [35] Our study showed that children of mothers with secondary or higher education significantly had reduced risk of child mortality. A possible reason is that women who are educated have more knowledge and good health seeking behaviour. This finding is supported by studies in Ethiopia, [11] Bangladesh [13,17] and Nigeria. [16] We also found that children born to mothers living in rural areas had a significantly increased risk of child mortality. This could be due to poor access to well-equipped health facilities in rural areas and traditional birth attendant practices. However, the finding is supported by similar studies conducted in Kenya, [12] Bangladesh [13] and Nigeria. [14,31] In this study, children born in North West region and South East region were significantly associated with increased risk of child death. Inequalities in the distribution of health facilities and the provision of health services could explain this observation. This finding is consistent with a similar study in Nigeria. [6] The risk of child mortality was significantly reduced for children whose mothers were married. Children who belong to households with family size of five or more people had significantly reduced risk of child mortality. We found that the risk of child mortality was significantly higher for children of 2-4 birth order and five or more birth order respectively. This finding is consistent with previous studies. [12,13,14,15] Children from households with parity between 3-4 children and 5 or more children respectively had a significantly lower risk of child mortality. This is consistent with the finding of similar study conducted in Tanzania. [35]

\section{Limitations of the Study}

Our study has some limitations but this does not invalidate our work. The study used cross-sectional secondary data; hence, causality between the predictor variables and outcome variable could not be established. Findings from our study are also affected by the structure of the questionnaire, mode of data collection, under-reporting of number of deaths and recall bias due to self-reported information.

\section{Conclusions}

Our study shows that there is no significant association between health facility-based delivery and child mortality. This implies that encouraging women to deliver their child in a health facility is not enough. However, being a child of women aged 25-34 years, being a child of women aged 35 years or older, being a child of a woman with secondary or higher education, being a child of a woman living in rural area, being a child of a woman living in North West region, being a child of a woman living in South East region, being a child of a married woman, being a child of a woman with more than five members, being a child of a woman with 2-4 birth order, being a child of a woman with five or more birth order, being a child of a woman with 3 and 4 children and being a child of a woman with five or more children were significantly associated with child mortality. Therefore, policy makers need to target these factors in their effort to reduce child mortality. The study has policy implications for the provision of functional health facilities within specified distance and improved quality of health service delivery. We recommend the adequate supply of skilled health professionals to health care facilities and the monitoring and training of unskilled birth attendants on safe delivery practices. Findings from our study suggest that health facility-based delivery is a complex issue that requires further research using the qualitative approach to understand the effect of health facility-based delivery on child mortality in Nigeria as well as explore the barriers to health facility-based delivery for women.

\section{Statement of Competing Interest}

The authors have no competing interests.

\section{References}

[1] Wang, H., Bhutta, Z.A., Coates, M.M., Coggeshall, M., Dandona, L., Diallo, K. et al, "Global, regional, national, and selected subnational levels of stillbirths, neonatal, infant, and under-5 mortality, 1980-2015: a systematic analysis for the Global Burden of Disease Study 2015”, Lancet, 388, 1725-74, 2016.

[2] World Health Organization, Global health observatory data: under 5 mortality. Available at

http://www.who.int/gho/child_health/mortality/mortality_under_fi ve_text/en/ Accessed 12 September 2017.

[3] USAID, Africa key facts and figures for child mortality. Available at https://www.usaid.gov/sites/default/files/documents/1860/Africa\% 20Key\%20Facts\%20and\%20Figures.pdf Accessed 12 September 2017.

[4] World Health Organization. (2017). World Health Statistics 2017. Geneva: World Health Organization.

[5] Wollum, A., Burstein, R., Fullman, N., Dwyer-Lindgren, L. and Gakidou, E, "Benchmarking health system performance across states in Nigeria: a systematic analysis of levels and trends in key maternal and child health interventions and outcomes, 20002013”, BMC Medicine, 13, 208, 2015.

[6] Adedini, S., Odimegwu, C., Imasiku, E.N.S., Ononokpono, D.N. and Ibisomi, L, "Regional variations in infant and child mortality in Nigeria: A multilevel analysis”, J Biosoc Sci, 47, 168-187, 2015

[7] Kembo, J. and Van Ginneken, J.K, "Determinants of infant and child mortality in Zimbabwe: results of multivariate hazard analysis”, Demographic Research, 21(13), 367-384, 2009. 
[8] Shah, M.S., Khalique, N. and Khan, Z, "Determinants of childhood mortality", Indian J Prev Soc Med, 42(2), 118-122, 2011.

[9] Wang, L, "Determinants of childhood mortality in LICs: empirical findings from demographic and health survey", Health Policy, 65(3), 277-99, 2003.

[10] Titaley, C.R., Dibley, M.J., Agho, K., Roberts, C.L. and Hall, J, "Determinants of neonatal mortality in Indonesia", BMC Public Health, 8, 232, 2008.

[11] Mekonnen, Y., Tenson, B., Telake, D.S., Degefie, T. and Bekele, A, "Neonatal mortality in Ethiopia: trends and determinants", BMC Public Health, 13:483, 2013.

[12] Ettarh, R. and Kimani, J, "Determinants of under-five mortality in rural and urban Kenya", Rural and Remote Health, 12(1), 1-9, 2012.

[13] Mondal, M.I., Hossain, M. and Ali, M, "Factors influencing infant and child mortality: a case study of Rajshahi District, Bangladesh", J Hum Ecol, 26(1), 31-39, 2009.

[14] Ezeh, O.K., Agho, K.E., Dibley, M.J., Hall, J. and Page, A.N, "Determinants of neonatal mortality in Nigeria: evidence from the 2008 demographic and health survey”, BMC Public Health, 14, 521, 1-10, 2014.

[15] Ezeh, O.K., Agho, K.E., Dibley, M.J., Hall, J. and Page, A.N, "Risk factors for postnatal, infant, child and under-5 mortality in Nigeria: a pooled cross-sectional analysis”, BMJ Open, 5, e006779, 2015.

[16] Akinyemi, J.O., Bamgboye, E.A. and Ayeni, O, "Trends in neonatal mortality in Nigeria and effects of bio-demographic and maternal characteristics”, BMC Pediatr, 15, 36, 2015.

[17] Abir, T., Agho, K.E., Page, A.N., Milton A.H. and Dibley, M.J, "Risk factors for under-5 mortality: evidence from Bangladesh Demographic and Health Survey, 2004-2011”, BMJ Open, 5, e006722, 2015.

[18] Kayode, G.A., Adekanmbi, V.T. and Uthman, O.A, 'Risk factors and a predictive model for under-five mortality in Nigeria: evidence from Nigeria demographic and health survey", BMC Pregnancy \& Childbirth, 12, 10, 2012.

[19] Omariba, D.W.R., Beaujot, R. and Rajulton, F, "Determinants of infant and child mortality in Kenya: an analysis controlling for frailty effects”, Popul Res Policy Rev, 26, 299-321, 2007.

[20] Fotso, J.C., Cleland, J., Mberu B. et al, "Birth spacing and child mortality: an analysis of prospective data from the Nairobi urban health and demographic surveillance system”, J Biosoc Sci, 45, 779-98, 2013.

[21] National Population Commission (NPC) [Nigeria] and ICF International, Nigeria Demographic and Health Survey 2013, NPC and ICF International, Abuja, Nigeria, and Rockville, Maryland, USA, 2014.

[22] Aremu, O., Lawoko, S. and Dalal, K, "Neighborhood socioeconomic disadvantage, individual wealth status and patterns of delivery care utilization in Nigeria: a multi-level discrete choice analysis", International Journal of Women's Health, 3, 167-174, 2011.

[23] Faye, A., Mariama, N. and Ibrahim, B, "Home birth in women who have given birth at least once in a health facility: contributory factors in a developing country", Acta Obstetricia et Gynecologica Scandinavica, 90, 11, 1239-1243, 2011.

[24] Gabrysch, S., Cousens, S., Cox, J. and Campbell, O.M.R, "The influence of distance and level of care on delivery place in rural Zambia: a study of linked national data in a geographic information system”, PLoS Med, 8, 1, e1000394, 2011.

[25] Kitui, J., Lewis, S. and Dawey, G, "Factors influencing place of delivery for women in Kenya: an analysis of Kenya demographic and health survey 2008/2009”, BMC Pregnancy \& Childbirth, 13, 40, 2013.

[26] Sharma, S.R., Poudyal, A.K., Devkota, B.M. and Singh, S, "Factors associated with place of delivery in rural Nepal", BMC Public Health, 14, 306, 2014.

[27] Kebede, A., Hassen, K. and Teklehaymanot, A.N, "Factors associated with institutional delivery service utilization in Ethiopia”, Int J Womens Health, 8, 463-475, 2016.

[28] Yaya, S., Bishwaji, T. and Ekholuenetale, M, "Factors associated with the utilization of institutional delivery services in Bangladesh”, PLoS ONE, 12(2), e0171573, 2017.

[29] Moyer, C.A. and Mustafa, A, "Drivers and deterrents of facility delivery in sub-Saharan Africa: a systematic review", Reproductive Health, 10, 40, 2013.

[30] Moyer, C.A., Dako-Gyeke, P. and Adanu, R.M, "Facility-based delivery and maternal and early neonatal mortality in sub-Saharan Africa: a regional review of literature”, Afr J Reprod Health, 17(3), 30-43, 2013.

[31] Oti, S.O. and Odimegwu, C, "Perinatal mortality in Nigeria: do place of delivery and delivery assistants matter?”, The Open Demography Journal, 4, 1-10, 2011.

[32] Tura, G., Fantahun, M. and Worku, A, "The effect of health facility delivery on neonatal mortality: systematic review and meta-analysis”, BMC Pregnancy and Childbirth, 13, 8: 1-9, 2013.

[33] Pal, S, "Impact of hospital delivery on child mortality: an analysis of adolescent mothers in Bangladesh”, Soc Sci Med, 143, 194-203, 2015.

[34] Titaley, C.R., Dibley, M.J., Agho, K. and Roberts, C.L, "Type of delivery attendants, place of delivery and risk of early neonatal mortality: analysis of the 1994-2007 Indonesia Demographic and Health Survey”, Health Policy Plan, 27(5), 405-416, 2012.

[35] Ajaari, J., Masanja, H., Weiner, R., Abokyi, S.A. and OwusuAgyei, S, "Impact of place of delivery on neonatal mortality in rural Tanzania”, Int J MCH AIDS, 1(1), 49-59, 2012.

[36] Chinkhumba, J., De Allegri, M., Muula, A.S and Robberstad, B, "Maternal and perinatal mortality by place of delivery in subSaharan Africa: a meta-analysis of population-based cohort studies”, BMC Public Health, 14, 1014, 2014.

[37] Aday, L.A. and Andersen, R.M, "A framework for the study of access to medical care", Health Services Research, 9, 208-20, 1974.

[38] Mosley, W.H. and Chen, C.C, "An analytical framework for the study of child survival in developing countries", Population and Development Review, 10, 25-45, 1984

[39] Lohela, T.J., Campbel, O.M.R. and Gabrysch, S, "Distance to care, facility delivery and early neonatal mortality in Malawi and Zambia”, PLoS ONE, 7(12), e52110, 2012. 